\title{
Intravenous lignocaine infusion facilitates acute rehabilitation after laparoscopic colectomy in the Chinese patients
}

\author{
Matthew WH Lee, Debriel YL Or, Alex CF Tsang *, Dennis CK Ng, PP Chen, Michael HY Cheung, \\ Raymond SK Li, HT Leong
}

\section{A B S T R A C T}

Introduction: Intravenous infusion of lignocaine has emerged in recent years as a feasible, costeffective, and safe method to provide postoperative analgesia. There is, however, no literature about this perioperative pain control modality in Chinese patients. This study aimed to determine whether perioperative intravenous lignocaine safely reduces postoperative pain, shortens postoperative ileus, and reduces the length of hospital stay in laparoscopic colorectal surgery.

Methods: Between September 2012 and May 2015, 16 patients who underwent elective laparoscopic resection of colorectal cancer and received a $1 \%$ lignocaine infusion for 24 hours postoperatively were studied. After surgery, categorical pain scores were obtained immediately, followed by hourly pain scores at rest. Pain scores at rest and with mobilisation, and patient satisfaction score were documented on postoperative day 1. Return of bowel function was measured by time of first flatus and bowel opening. The patient's rehabilitation was assessed by time taken to tolerate diet, full mobilisation, and length of hospital stay.

Results: The median (interquartile range) selfreported pain scores at 2 hours and 6 hours after

This article was published on 27 Jan 2017 at www.hkmj.org. surgery were $1.5(0-4)$ and $2(0-3)$, respectively. The median pain scores at rest and mobilisation on postoperative day 1 were $1(0-2.5)$ and $2(2.5-5)$, respectively, with a median satisfaction score of 7.5 (7-9). The median times to first flatus and first bowel opening were 21 (18-35) hours and 3 (1-3) days, respectively. No patient had postoperative ileus. The median times to tolerating diet and mobilisation were 1 (1-1) day and 2 (2-3) days, respectively. The median postoperative stay was 6 (5-8) days.

Conclusions: Intravenous lignocaine is a safe and effective postoperative analgesic in a Chinese population. It enhances the rehabilitation process for patients following laparoscopic resection of colorectal cancer.

\section{Hong Kong Med J 2017;23:441-5}

DOI: $10.12809 / \mathrm{hkmj} 164984$

\author{
${ }^{1}$ MWH Lee, MB, ChB \\ ${ }^{2}$ DYL Or, FHKAM (Anaesthesiology) \\ ACF Tsang *, FHKAM (Surgery) \\ ${ }^{3}$ DCK Ng, FHKAM (Surgery) \\ PP Chen, FHKAM (Anaesthesiology) \\ ${ }^{3}$ MHY Cheung, FHKAM (Surgery) \\ ${ }^{3}$ RSK Li, FHKAM (Surgery) \\ ${ }^{3}$ HT Leong, FHKAM (Surgery)
}

1 Department of Orthopaedics, Queen Elizabeth Hospital, Jordan, Hong Kong

Department of Anaesthesiology and Operating Service, North District Hospital, Sheung Shui, Hong Kong

Department of Surgery, North District Hospital, Sheung Shui, Hong Kong

* Corresponding author: alextsang81@yahoo.com

New knowledge added by this study

- This is the first case series in Hong Kong to show that intravenous lignocaine infusion is safe in a Chinese population as postoperative analgesia. Clinical safety and effectiveness was positive in this study.

Implications for clinical practice or policy

Intravenous infusion of lignocaine can help to enhance postoperative recovery for patients following laparoscopic resection of colorectal cancer. Large-scale structured studies should be carried out to confirm these findings.

\section{Introduction}

Over the past couple of decades, there has been a move towards fast-track surgery designed to reduce postoperative morbidities and length of hospital stay. ${ }^{1}$ Laparoscopic methods for colonic surgery have accelerated postoperative recovery by reducing the time required for bowel function recovery and enhancing postoperative mobilisation. ${ }^{2}$
Postoperative ileus, however, remains a common reason for prolonged hospital stay following major abdominal surgery. Although its pathophysiology is multifactorial, use of opioids as postoperative analgesia is thought to contribute to the problem. ${ }^{3,4}$ Therefore, safe and effective postoperative pain control with minimal use of opioids is essential to enhance recovery. ${ }^{5}$ 


\section{靜脈注射利多卡因加快接受腹腔鏡結腸切除的 華籍病人的術後康復過程

\author{
李韋瀚、柯燕玲、曾致鋒、吳宗基、曾煥彬、張浩然、 \\ 李兆奇、梁慶達
}

引言：靜脈輸注利多卡因經已成為近年術後鎮痛的一個可行、具成本 效益和安全的方法。然而, 文獻中未有關於這種圍手術期鎮痛方法對 華籍患者的成效。本研究旨在探討圍手術期靜脈注射利多卡因可否安 全降低術後疼痛、縮短術後腸梗阻時間, 以及縮短腹腔鏡結直腸手術 的住院時間。

方法：2012年9月至2015年5月期間有 16名患者接受腹腔鏡切除大腸 癌手術並接受 24 小時輸注 $1 \%$ 利多卡因。我們記錄患者不同位置的術後 即時疼痛評分, 並休息期間每小時的疼痛評分。術後第 1 天則記錄靜 息時和走動時的疼痛評分, 以及患者的滿意度評分。透過第一次腸排 氣和肛門排便的時間測量腸功能的恢復。通過耐受飲食、全走動和住 院時間來評估患者的康復進度。

結果：術後2小時和6小時自我疼痛評分的中位數（四分位間距）分 別為 $1.5(0-4)$ 和 $2(0-3)$ 。術後第 1 天的靜息和走動疼痛得分分別 為1（0-2.5）和2（2.5-5）。患者的平均滿意度得分為7.5（7-9）。 第一次腸排氣和肛門排便的時間分別為21（18-35）小時和3（1-3) 天。所有患者均無術後腸梗阻。可接受耐受飲食和走動的時間分別為 1 (1-1) 天和2（2-3）天。術後住院時間為6（5-8）天。

結論：靜脈輸注利多卡因可作為腹腔鏡結腸切除華籍患者術後鎮痛的 一個安全和有效的方法, 它能加快病人的康復過程。

The advantages of continuous infusion of thoracic epidural analgesia (TEA) compared with intravenous (IV) patient-controlled analgesia with opioid have been studied. The results show that TEA significantly improves early analgesia requirement following laparoscopic colectomy with an opioidsparing effect. Nonetheless TEA is associated with other adverse reactions such as urinary retention, hypotension, epidural haematoma, and abscess formation. ${ }^{6}$ Intravenous infusion of lignocaine has emerged in recent years as a feasible, costeffective, and safe method to provide postoperative analgesia. ${ }^{7}$ Recent randomised controlled trials have shown that the combined analgesic, antiinflammatory, and antihyperalgesic properties of IV lignocaine improve outcomes and shorten hospital stay following colorectal surgery. ${ }^{8}$ There is level I (PRISMA: Preferred Reporting Items for Systematic Reviews and Meta-Analyses) evidence that IV lignocaine infusions are opioid-sparing and significantly reduce pain scores at rest and during activity, nausea, vomiting, duration of ileus after abdominal surgery, and length of hospital stay. Perioperative IV administration of lignocaine also has a preventive analgesic effect following a wide range of operations. ${ }^{9-11}$

Currently there is no literature about this perioperative pain control modality in the Chinese patients. In the following account, we present a case series of Chinese patients who underwent laparoscopic colorectal surgery and received a perioperative IV lignocaine infusion.

\section{Methods}

We reviewed cases of patients who underwent elective laparoscopic resection of colorectal cancer and received a lignocaine infusion as postoperative analgesia between September 2012 and May 2015 at North District Hospital in Hong Kong. This study aimed to determine whether postoperative IV lignocaine infusion would provide adequate analgesia, shorten the duration of postoperative ileus, reduce postoperative complications, enhance rehabilitation, and shorten hospital stay. This study was done in accordance with the principles outlined in the Declaration of Helsinki.

\section{Anaesthesia}

All patients were assessed preoperatively by an anaesthetist to exclude any contra-indications to use of IV lignocaine. Routine consent for anaesthesia was obtained with clear choices offered for postoperative analgesia and the relevant risks explained to the patient. The choices for postoperative analgesia included epidural analgesia, IV lignocaine infusion, and IV patient-controlled analgesia with morphine. Intravenous lignocaine was offered when patients refused or were contra-indicated for epidural analgesia. If patients were not suitable for either epidural analgesia or IV lignocaine, IV patientcontrolled analgesia with morphine was offered. The anaesthetic technique was standardised for all patients.

All patients received an IV bolus injection of lignocaine $1.5 \mathrm{mg} / \mathrm{kg}$ over 20 minutes on induction followed by a continuous infusion of $1.5 \mathrm{mg} / \mathrm{kg} / \mathrm{h}$ intra-operatively. The $1 \%$ lignocaine infusion was continued at a rate of $1 \mathrm{mg} / \mathrm{kg} / \mathrm{h}$ for 24 hours postoperatively, delivered through a GemStar infusion device with the fixed calculated dose set up by the case anaesthetist. For safety reasons, the lignocaine infusion was connected to a dedicated IV line to avoid accidental bolus administration. General anaesthesia was induced with fentanyl 1-2 $\mu \mathrm{g} / \mathrm{kg}$, propofol 2-3 $\mathrm{mg} / \mathrm{kg}$, and cisatracurium $0.15-0.2$ $\mathrm{mg} / \mathrm{kg}$ for intubation. Anaesthesia was maintained with oxygen in room air or nitrous oxide and isoflurane or sevoflurane at an end-tidal anaesthetic concentration of approximately 1 minimal alveolar concentration. Ketorolac 15-30 mg was administered on induction if not contra-indicated clinically. Intravenous tramadol 50-100 mg and morphine was used intra-operatively for analgesia as decided by the list anaesthetist. Wound infiltration of local anaesthetic, $0.25 \%$ levobupivacaine $20 \mathrm{~mL}$, was administered by the surgeon at the end of surgery. 


\section{Surgical procedure}

Patients who had colorectal cancer and underwent elective laparoscopic colorectal resection were recruited into the study. All patients had colorectal cancer but the surgical procedure performed depended on the location of the tumour and the international standard. The surgeries included: laparoscopic right hemicolectomy $(\mathrm{n}=2)$, laparoscopic left hemicolectomy $(\mathrm{n}=3)$, laparoscopic sigmoidectomy $(\mathrm{n}=5)$, laparoscopic anterior resection of rectum $(n=1)$, laparoscopic lower anterior resection with total mesorectal excision and stoma formation $(\mathrm{n}=4)$, and laparoscopic abdominoperineal resection $(\mathrm{n}=1)$. All patients had four to five small incisions for the laparoscopic procedure together with one larger 6- to $8-\mathrm{cm}$ abdominal incision for specimen retrieval. For the patient with laparoscopic abdominoperineal resection, a larger wound for specimen retrieval was made over the perineal region instead of the abdomen.

\section{Postoperative analgesia}

All patients were prescribed regular oral paracetamol $500 \mathrm{mg}$ to $1 \mathrm{~g} 3$ to 4 times per day. Regular oral diclofenac SR $100 \mathrm{mg}$ daily for 3 days was prescribed if not contra-indicated. As required, IV tramadol $50 \mathrm{mg}$ every 6 to 8 hours was given if pain was not adequately controlled. Rescue subcutaneous morphine was prescribed in the protocol for severe uncontrolled pain.

\section{Outcome measures}

All postoperative data were collected prospectively. The acute pain service and ward nurses followed the clinical plan that was devised by both the surgical and pain team.

After surgery, a categorical pain score (divided into none, mild, moderate, or severe pain) was obtained immediately in the postoperative care unit by recovery nurses. After the patient was discharged to the ward, pain scores were obtained by ward nurses on a numerical rating scale at rest hourly for 24 hours until lignocaine infusion was stopped. Patients would be reviewed by acute pain management team before lignocaine infusion was stopped and pain scores on postoperative day 1 were obtained at rest and during mobilisation. The numerical rating scale scored pain from 0 to 10 with 0 being no pain and 10 being the worst pain imaginable. Pain scores are continuous variables and are presented as median (interquartile range [IQR]) scores against time. Patient satisfaction score from 0 to 10 was also assessed by the acute pain management team. The presence of nausea, vomiting, dizziness, and other possible side-effects was documented. Intra-operative and postoperative analgesic consumption was recorded. All patients were monitored by cardiac monitor intra-operatively by anaesthetists and postoperatively in the recovery room by nurses. When patients were discharged to the ward, they were monitored for the next 24 hours until the end of IV lignocaine infusion with vital signs recorded every hour, including blood pressure, pulse, saturation, and continuous cardiac monitoring. There was no recorded cardiac arrhythmia event noted for any patient.

Return of bowel function was assessed by calculating the time from end of surgery to the passage of first flatus and first bowel opening. Postoperative rehabilitation was assessed by the time taken to tolerate diet and achieve full mobilisation and the length of hospital stay. These data are expressed as median (IQR) scores.

\section{Results}

Sixteen patients were studied with a mean $( \pm$ standard deviation) age of $66 \pm 10$ years. All were classified as American Society of Anesthesiologists grade I to III. Demographic data and duration of surgery are shown in Table 1.

During IV lignocaine infusion, four patients experienced nausea, one vomited, and two complained of mild dizziness. No serious adverse reactions were reported. All patients tolerated and completed the infusion of lignocaine.

In the postoperative care unit, most patients experienced none or mild pain. Only one patient complained of severe pain and required a fentanyl bolus for rescue analgesia. The self-reported pain scores are shown in Table 2. In addition to regular paracetamol, five patients requested IV tramadol for rescue analgesia in the first 24 hours postoperatively; these patients received tramadol 50-150 mg. No patient requested morphine during the first 24 hours postoperatively. Of the 16 patients, 11 showed

TABLE I. Demographic data and duration of surgery of the patients $(n=16)$

\begin{tabular}{|c|c|}
\hline & $\begin{array}{l}\text { No. of patients } \\
\text { or mean } \pm S D\end{array}$ \\
\hline Male / female & $10 / 6$ \\
\hline Age (years) & $66 \pm 10$ \\
\hline ASA grade I / II / III & $1 / 11 / 4$ \\
\hline \multicolumn{2}{|l|}{ Type of surgery } \\
\hline Laparoscopic right hemicolectomy & 2 \\
\hline Laparoscopic left hemicolectomy & 3 \\
\hline Laparoscopic sigmoidectomy & 5 \\
\hline Laparoscopic lower anterior resection & 5 \\
\hline Abdominal perineal resection & 1 \\
\hline Duration of surgery (mins) & $171 \pm 51$ \\
\hline
\end{tabular}

Abbreviations: ASA = American Society of Anaesthesiologists; $\mathrm{SD}=$ standard deviation 
TABLE 2. Self-reported pain scores

\begin{tabular}{lc}
\hline Time after surgery & Median (IQR) pain score* \\
\hline 2 Hours & $1.5(0-4.0)$ \\
6 Hours & $2.0(0-3.0)$ \\
1 Day (rest) & $1.0(0-2.5 .0)$ \\
1 Day (mobilise) & $2.0(2.5-5.0)$ \\
\hline
\end{tabular}

Abbreviation: IQR = interquartile range

* Pain was reported on a numerical rating scale 0 - 10 , with 0 being no pain and 10 the worst pain

TABLE 3. Outcome measures

\begin{tabular}{lc}
\hline Outcome measure & $\begin{array}{c}\text { Median (interquartile } \\
\text { range) }\end{array}$ \\
\hline Time to first flatus (hours) & $21(18-35)$ \\
Time to first bowel opening (days) & $3(1-3)$ \\
Time to tolerate diet (days) & $1(1-1)$ \\
Time to mobilisation (days) & $2(2-3)$ \\
Postoperative stay (days) & $6(5-8)$ \\
\hline
\end{tabular}

overall satisfaction with the analgesia with median satisfaction score of 7.5 (7-9).

As seen in Table 3, the median times to first flatus and first bowel opening in the postoperative period were 21 (18-35) hours and 3 (1-3) days, respectively. The median times to tolerating diet and mobilisation were 1 (1-1) day and 2 (2-3) days, respectively. No patient had postoperative ileus. Only one patient had acute retention of urine that delayed discharge from hospital. Three other patients had a prolonged hospital stay due to social problems.

There was no documented postoperative arrhythmia for any patient.

\section{Discussion}

Although this is a small case-series review, we have shown that lignocaine infusion is a safe and feasible means of postoperative pain control for patients undergoing laparoscopic colorectal resection. There was no major or serious adverse reaction such as cardiac arrhythmia during the lignocaine infusion. We also demonstrated that lignocaine infusion provided effective analgesia over the first 24 hours with acceptable pain score, low rescue opioid consumption, and good patient satisfaction score. Our results are consistent with the literature. Harvey et $\mathrm{al}^{12}$ observed that pain scores were decreased when a lignocaine infusion was administered compared with a group who received IV infusion of normal saline. Kaba et $\mathrm{al}^{13}$ also demonstrated that their lignocaine group required $50 \%$ less opioid during the first 24 hours postoperatively. Similar results were reported in other randomised controlled trials demonstrating that IV lignocaine has an opioid-sparing effect as an adjuvant analgesic. ${ }^{7,14} \mathrm{~A}$ recent meta-analysis by McCarthy et al $^{15}$ examined the overall efficacy of IV lignocaine on postoperative analgesia and recovery from surgery in patients undergoing various surgical procedures. It concluded that IV lignocaine infusion in the perioperative period has clear advantages in patients undergoing abdominal surgery in terms of both pain control and bowel motility.

Our study also observed that IV lignocaine resulted in rapid recovery of bowel function and mobilisation. The median time for return of flatus and ability to tolerate an oral diet was within 24 hours. The median (IQR) time for bowel opening was 3 (1-3) days. These results are similar to the findings of Kaba et $\mathrm{al}^{13}$ who showed that lignocaine infusion improved postoperative bowel function. In that study, defaecation occurred almost 1 day earlier in the lignocaine group compared with the group who received normal saline. The reasons for postoperative ileus are multifactorial, including use of opioid analgesia, the sympathetic response, and visceral inflammatory response resulting from surgery. ${ }^{16}$ A lignocaine infusion may shorten the time to bowel opening by decreasing opioid use, limiting the inflammatory response, and having a direct inhibitory effect on the sympathetic nervous system of the mesenteric nervous plexus resulting in enhanced bowel contractility. ${ }^{17}$

A meta-analysis showed that continuous IV administration of lignocaine significantly reduces the length of hospital stay when compared with controls. ${ }^{17}$ In our study, however, the median hospital stay was 6 days, similar to our usual experience. We are evaluating the possible reasons for the lack of impact on hospital stay. One of the reasons may be related to patient expectations and preference for a longer hospital stay after major surgery. Another possible reason is the similar rehabilitation care pathway for the two groups of patients that when strictly followed tended to negate the advantages of IV lignocaine.

\section{Conclusions}

This review shows promising results demonstrating that IV lignocaine is a safe and effective postoperative analgesia in a Chinese population. It also provides comparable outcomes to those reported worldwide that postoperative lignocaine can provide a beneficial rehabilitation effect for patients who have undergone laparoscopic colorectal surgery. This provides a good platform from which to design a randomised controlled trial in the Chinese population.

\section{Declaration}

The authors declared no conflicts of interest in this study. 


\section{References}

1. Kehlet H, Dahl JB. Anaesthesia, surgery, and challenges in postoperative recovery. Lancet 2003;362:1921-8.

2. Reza MM, Blasco JA, Andradas E, Cantero R, Mayol J. Systematic review of laparoscopic versus open surgery for colorectal cancer. Br J Surg 2006;93:921-8.

3. Baig MK, Wexner SD. Postoperative ileus: a review. Dis Colon Rectum 2004;47:516-26.

4. Taguchi A, Sharma N, Saleem RM, et al. Selective postoperative inhibition of gastrointestinal opioid receptors. N Engl J Med 2001;345:935-40.

5. Kuhry E, Schwenk W, Gaupset R, Romild U, Bonjer J. Long-term outcome of laparoscopic surgery for colorectal cancer: a cochrane systematic review of randomized controlled trials. Cancer Treat Rev 2008;34:498-504.

6. Senagore AJ, Delaney CP, Mekhail N, Dugan A, Fazio VW. Randomized clinical trial comparing epidural anaesthesia and patient-controlled analgesia after laparoscopic segmental colectomy. Br J Surg 2003;90:1195-9.

7. Koppert W, Weigand M, Neumann F, et al. Perioperative intravenous lidocaine has preventive effects on postoperative pain and morphine consumption after major abdominal surgery. Anesth Analg 2004;98:1050-5.

8. Herroeder S, Pecher S, Schönherr ME, et al. Systemic lidocaine shortens length of hospital stay after colorectal surgery: a double-blinded, randomized, placebo-controlled trial. Ann Surg 2007;246:192-200.

9. Vigneault L, Turgeon AF, Côté D, et al. Perioperative intravenous lignocaine infusion for postoperative pain control: a meta-analysis of randomized control trials. Can J
Anaesth 2011;58:22-37.

10. Sun Y, Li T, Wang N, Yun Y, Gan TJ. Perioperative systemic lidocaine for postoperative analgesia and recovery after abdominal surgery: a meta-analysis of randomized control trials. Dis Colon Rectum 2012;55:1183-94.

11. Barreveld A, Witte J, Chahal H, Durieux ME, Strichartz G. Preventive analgesia by local anesthetics: the reduction of postoperative pain by peripheral nerve blocks and intravenous drugs. Anesth Analg 2013;116:1141-61.

12. Harvey KP, Adair JD, Isho M, Robinson R. Can intravenous lidocaine decrease postsurgical ileus and shorten hospital stay in elective bowel surgery? A pilot study and literature review. Am J Surg 2009;198:231-6.

13. Kaba A, Laurent SR, Detroz BJ, et al. Intravenous lidocaine infusion facilitates acute rehabilitation after laparoscopic colectomy. Anesthesiology 2007;106:11-8.

14. Groudine SB, Fisher HA, Kaufman RP Jr, et al. Intravenous lidocaine speeds the return of bowel function, decreases postoperative pain, and shortens hospital stay in patients undergoing radical retropubic prostatectomy. Anesth Analg 1998;86:235-9.

15. McCarthy GC, Megalla SA, Habib AS. Impact of intravenous lidocaine infusion on postoperative analgesia and recovery from surgery: a systematic review of randomized controlled trials. Drugs 2010;70:1149-63.

16. Luckey A, Livingston E, Taché Y. Mechanisms and treatment of postoperative ileus. Arch Surg 2003;138:206-14.

17. Marret E, Rolin M, Beaussier M, Bonnet F. Meta-analysis of intravenous lidocaine and postoperative recovery after abdominal surgery. Br J Surg 2008;95:1331-8. 